\title{
Pengaruh Disiplin dan Motivasi Belajar terhadap Prestasi Belajar Bahasa Indonesia (Survei pada SMP Negeri di Kabupaten Bogor)
}

\author{
Maspupah \\ Universitas Indraprasta PGRI \\ Jalan Nangka No. 58 C/TB. Simatupang, Tanjung Barat, Jakarta Selatan 12530 \\ maspupah_19@gmail.com
}

\begin{abstract}
The purpose of this research is to find out the effect of discipline and learning motivation on the Indonesian learning achievement.The research used a survey method using multiple regression techniques. From the results of data analysis,conclusions are obtained asthere follows: 1) there is the effect of discipline and learning motivation together on the achievement of learning Indonesian significantly student of SMP Negeri in Regency Bogor. This is evidenced by the value Fhitung = 7,659 and Sig.0,001 <0,05. Meanwhile, the multiple regression line equation can be expressed with $Y=39,498+0,173 X 1+0,298$. This means that the variable discipline and leraning motivation gives a positive contribution $17 \%$ to the variable in Indonesian learning achievement. 2) there is the effect level of discipline on the achievement of learning Indonesian significantly student of SMP Negeri in Regency Bogor. This is evidenced by the value Thitung = 2,007 and Sig. 0,048<0,05. The variable discipline gives a contribution 5,28\% to increasing Indonesian learning achievement. 3) there is the effect level learning motivation on the achievement of learning Indonesian significantly student of SMP Negeri in Regency Bogor. This is evidenced by the value Thitung = 3,116 and Sig. 0,003 < 0,05. The variable learning motivation on the achievement of Indonesian learning gives a contribution 11,7\% to increasing Indonesian learning achievement.
\end{abstract}

Keywords: Discipline, Learning Motivation, the Indonesian learning achievement.

\begin{abstract}
Abstrak
Tujuan dari penelitian ini adalah untuk mengetahui pengaruh disiplin dan motivasi belajar terhadap prestasi belajar Bahasa Indonesia. Metode penelitian yang digunakan adalah metode survey dengan menggunakan teknik regresi ganda. Dari hasil analisis data diperoleh kesimpulan sebagai berikut: 1) Terdapat pengaruh yang signifikan disiplin dan motivasi belajar secara bersama-sama terhadap prestasi belajar bahasa Indonesia siswa SMP Negeri di Kabupaten Bogor. Hal ini dibuktikan dengan perolehan nilai Sig. 0,001 $<0,05$ dan $F_{h}=7,659$. Sementara itu, persamaan garis regresi ganda dapat dinyatakan dengan $\hat{Y}=39,498+0,173 \mathrm{X} 1+0,298$. Hal ini memiliki pengertian bahwa variabel disiplin dan motivasi belajar memberikan kontribusi positif terhadap variabel prestasi belajar Bahasa Indonesia. secara bersama-sama variable disiplin siswa dan motivasi belajar memberikan kontribusi sebesar $17 \%$ terhadap variable prestasi belajar Bahasa Indonesia. 2) Terdapat pengaruh yang signifikan disiplin terhadap prestasi belajar bahasa Indonesia siswa SMP Negeri di Kabupaten Bogor. Hal ini dibuktikan dengan perolehan nilai Sig. 0,048 $<0,05$ dan $t_{h}=2.007$. variabel disiplin memberikan kontribusi sebesar 5,28 \% terhadap peningkatan prestasi belajar bahasa Indonesia. 3) Terdapat pengaruh yang signifikan motivasi belajar terhadap prestasi belajar bahasa Indonesia siswa SMP Negeri di Kabupaten Bogor. Hal ini dibuktikan dengan perolehan nilai Sig. 0,003 < 0,05 dan $\mathrm{t}_{\mathrm{h}}=3.116$. variabel motivasi belajar memberikan kontribusi sebesar $11,7 \%$ terhadap peningkatan prestasi belajar bahasa Indonesia.
\end{abstract}

Kata Kunci: Disiplin, Motivasi Belajar, Prestasi Belajar Bahasa Indonesia.

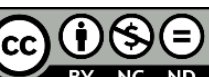

Creative Commons Attribution-NonCommercial-NoDerivatives 4.0 International License 


\section{PENDAHULUAN}

Disiplin berasal dan bahasa Latin "disciplina" yang berarti "pengajaran" atau "latihan". Ada juga yang mengatakan berasal dari kata "disciple" yang berarti siswa, pengikut setia, penganut terhadap paham seorang guru, ajaran atasi aliran seni. Dari uraian tersebut dapat dilihat bahwa kata disiplin mempunyai konotasi "kepatuhan " dan "ketaatan" baik terhadap ajaran, aliran atau paham. Poerwadarminto (2002) mengartikan disiplin dalam Kamus Besar Bahasa Indonesia, sebagai "proses latihan batin dan watak dengan maksud supaya perbuatannya selalu menaati tata tertib". Sukadji (1988) mengemukakan disiplin sebagai proses, bimbingan yang bertujuan untuk menanamkan pola tingkah laku tertentu, kebiasaan tertentu, atau rnembentuk manusia dengan ciri-ciri tertentu, terutama meningkatkan kualitas mental dan moral.

Watkins, dkk. dalam Moenir (2010) berpendapat bahwa "Disiplin dalam pengertian utuh adalah suatu kondisi atau sikap yang ada pada semua anggota organisasi yang tunduk dan taat pada aturan organisasi”. Malayu (2002) menyatakan bahwa "kedisiplinan adalah kesadaran dan kesediaan seseorang menaati semua peraturan perusahaan dan norma-norma sosial yang berlaku". Kesadaran adalah sikap seseorang mentaati semua peraturan dan sadar akan tugas dan tanggung jawabnya. Kesediaan adalah sikap, tingkah laku dan perbuatan seseorang yang sesuai dengan peraturan baik secara tertulis maupun tidak tertulis.

Disiplin diartikan sebagai kepatuhan dan ketaatan terhadap semua norma yang berlaku dalam lingkungan tertentu yang merupakan pancaran hati nurani berdasarkan pemahaman rasional dan keyakinan akan kebenaran serta kemanfaatan norma tersebut. Disiplin yang dikaitkan dengan belajar dapat diartikan sebagai disiplin belajar.

Moenir (2010) mengungkapkan bahwa ada dua jenis disiplin yang sangat dominan dalam usaha untuk menghasilkan sesuatu yang dikehendaki organisasi. Kedua disiplin itu ialah disiplin dalam hal waktu dan disiplin dalam hal perbuatan. Kedua disiplin tersebut merupakan kesatuan yang tidak dapat dipisahkan serta saling memengaruhi. Disiplin waktu apabila seseorang memulai dan mengakhiri pekerjaan tepat waktu, sedangkan disiplin perbuatan mengharuskan seseorang mengikuti dengan ketat perbuatan atau langkah tertentu dalam perbuatan agar mencapai dan menghasilkan sesuatu dengan standar yang telah ditetapkan. Kedua disiplin itu harus dilaksanakan serentak dan tidak separuh-separuh. Disiplin waktu tanpa disertai disiplin perbuatan tidak ada artinya sedangkan disiplin perbuatan tanpa disiplin waktu tidak ada manfaatnya.

Belajar dalam arti formal terjadi di sekolah, selain itu siswa dituntut untuk belajar di rumah meliputi pengulangan apa yang telah dipelajari di sekolah dan persiapan sekolah hari berikutnya. Disiplin belajar dapat berupa disiplin belajar di sekolah dan disiplin belajar di rumah. Slameto (2010) mengungkapkan bahwa "agar siswa belajar lebih maju, siswa harus disiplin baik di sekolah maupun di rumah dan di perpustakaan". Disiplin belajar adalah pengendalian diri siswa terhadap bentukbentuk aturan baik tertulis maupun tidak tertulis yang telah diterapkan oleh siswa yang bersangkutan maupun berasal dari luar serta bentuk kesadaran akan tugas dan tanggung jawabnya sebagai pelajar, baik disiplin di sekolah maupun disiplin di 
rumah dengan tidak melakukan sesuatu yang dapat merugikan tujuan dari proses belajarnya menghargai pendapat orang lain; gerak-gerik dan mimik yang tepat; kenyaringan suara; kelancaran berbicara; relevansi; penalaran dan logis; dan penguasaaan topik pembicaraan/ bahan pembicaraan

Menurut Pintrich dan Schunk dalam Setiawati (1996) mengungkapkan bahwa "Motivasi adalah proses di mana dengan kehadirannya, maka aktivitas yang mengarah pada tujuan dikuatkan dan berlangsung terus", sedangkan menurut Morgan (dalam Setiawati, 1996), "Motivasi adalah kekuatan mendorong dan menarik yang mengakibatkan terpeliharanya perilaku yang terarah pada suatu tujuan tertentu". Secara khusus Franken dalam Setiawati (1996) menyebutkan bahwa "Motivasi belajar adalah motivasi untuk mengatasi rintangan, menggunakan daya-upaya, bekerja keras mengerjakan hal yang sulit sebaik dan secepat mungkin".

Motivasi lebih merupakan proses dari pada produk. Sebagai suatu proses, motivasi tak dapat diobservasi secara langsung, tetapi dapat disimpulkan dari perilaku-perilaku tertentu, seperti pemilihan tugas, upaya, persistensi, verbalisasi seperti "saya benar-benar tidak suka mengerjakan hal ini" (Pintrich dan Schunk, dalam Setiawati, 1996). Dengan demikian, dapat dikatakan bahwa walaupun tak dapat dilihat secara langsung, motivasi dapat diukur dengan perilaku-perilaku tertentu.

Dalam motivasi terkandung tujuan-tujuan yang merupakan pendorong dan pengarah tindakan. Pandangan kognitif terhadap motivasi menekankan pentingnya tujuan. Tujuan kemungkinan tidak dapat diformulasikan dengan baik, dan mungkin berubah bersama dengan diperolehnya pengalaman. Tetapi yang pasti adalah, bahwa "individu memiliki sesuatu pada pikirannya, yang membuat mereka mencoba untuk mencapai atau menghindarinya". Faktor yang dapat mempengaruhi keberhasilan siswa dalam prestasi berbicara bahasa Inggris terbagi dua, ada internal dan eksternal. Darmadi (2009) menyatakan bahwa dalam Kemampuan Dasar Mengajar, faktor-faktor tersebut digolongkan menjadi empat, yakni (a) bahan atau materi yang dipelajari; (b) lingkungan; (c) faktor instrumental; dan (d) kondisi peserta didik. Faktor-faktor tersebut baik secara terpisah maupun bersama-sama memberikan kontribusi tertentu terhadap prestasi belajar peserta didik.

Faktor eksternal yang dapat memengaruhi prestasi belajar peserta didik dapat digolongkan kedalam faktor sosial dan nonsosial. Faktor sosial menyangkut hubungan antara manusia yang terjadi dalam berbagai situasi sosial. Seperti, lingkungan keluarga, sekolah, teman, dan masyarakat pada umumnya. Faktor nonsosial adalah yang menyangkut lingkungan alam dan fisik. Seperti keadaan rumah, ruang belajar, buku-buku sumber, dan sebagainya.

Untuk tercapainya hasil belajar yang maksimal kondisi yang disebutkan di dalam faktor eksternal tersebut hendaknya dapat diimplementasikan dan diberikan perhatian sebaik mungkin sehingga peserta didik akan merasa nyaman dalam proses pembelajarannya dan hasilnya pun diharapkan akan lebih maksimal. Faktor internal merupakan faktor dari diri sendiri. Brata (dalam Darmadi, 2009) mengklasifikasikan faktor internal mencakup: (a) faktor-faktor fisikologis, yang menyangkut keadaan jasmani atau fisik individu, yang dapat dibedakan menjadi dua macam yaitu keadaan jasmani pada umumnya dan keadaan fungsi-fungsi

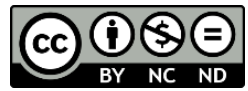


jasmani tertentu terutama pada panca indera, dan (b) faktor-faktor psikologis, yang berasal dari dalam diri seperti intelegensi, minat, sikap dan motivasi.

Prestasi atau hasil belajar tidak terlepas dari faktor internal dan eksternal dari seseorang. Hal ini berarti ketika dua faktor tersebut dapat dimaksimalkan fungsinya maka hasilnya pun dapat lebih baik. Darmadi (2009) juga menambahkan bahwa "Intelegensi merupakan dasar potensial bagi pencapaian hasil belajar". Artinya hasil belajar yang dicapai bergantung pada tingkat intelegensi seseorang. Semakin tinggi tingkat intelegensinya maka makin tinggi pula kemungkinan hasil prestasi belajarnya.

\section{METODE}

Metode yang digunakan dalam penelitian ini adalah metode survei dengan menggunakan teknik analisis korelasi dan regresi. Metode ini memberi gambaran tentang variabel-variabelyang ditemukan, sekaligus menyelidiki pengaruh antara variabel. Oleh karena itu, metode ini akan mengungkapkan data faktual berdasarkan informasi yang ditemukan. Analisis korelasi dan regresi digunakan untuk mengetahui: (1) pengaruh antara pasangan skor variabel disiplin $\left(\mathrm{X}_{1}\right)$ terhadap prestasi belajar siswa bahasa indonesia (Y), (2) pengaruh antara pasangan skor variabel motivasi belajar $\left(\mathrm{X}_{2}\right)$ terhadap prestasi belajar siswa bahasa indonesia $(\mathrm{Y})$, dan (3) pengaruh antara pasangan skor variabel disiplin $\left(X_{1}\right)$ dan motivasi belajar $\left(\mathrm{X}_{2}\right)$ secara bersama-sama terhadap variabel prestasi belajar siswa bahasa indonesia (Y).

Sugiyono (2007) berpendapat bahwa populasi adalah wilayah generalisasi yang terdiri atas objek/subjek yang mempunyai kualitas dan karakteristik tertentu yang ditetapkan oleh peneliti untuk dipelajari dan kemudian ditarik kesimpulannya. Adapun populasi dalam penelitian ini seluruh siswa kelas VIII SMP Negeri di Kabupaten Bogor yang berjumlah 780 orang siswa.

Arikunto (2010) menyatakan bahwa sampel adalah sebagian atau wakil dari populasi yang diteliti. Jika yang diteliti populasinya kurang dari 100 lebih baik subjeknya diambil semua sehingga penelitiannya merupakan penelitian populasi. Sementara jika lebih dari 100 maka boleh diambil antara $10-15 \%$ atau 20-25\%. Atas dasar argumentasi diatas maka dalam hal ini sampel yang akan ditetapkan dalam penellitian adalah 10\%-15\% dari populasi. Diketahui bahwa siswa kelas VIII SMP Negeri di Kabupaten Bogor berjumlah 780 siswa maka jika diambil 10\%-15\% berarti yang dijadikan sampel adalah 78-117 siswa. Jadi, jumlah sampel dalam penelitian ini adalah $10 \%$ x 780 siswa $=78$ orang siswa.

Teknik Pengumpulan data yang digunakan adalah dengan menggunakan metode pengisian angket /kuesioner, wawancara, kepustakaan, dan dokumentasi. 
Diskursus: Jurnal Pendidikan Bahasa Indonesia

Vol. 2, No. 1, April 2019, pp. 55-61

p-ISSN: 2615-4935

e-ISSN: 2615-4943

\section{HASIL DAN PEMBAHASAN}

Tabel 1. Uji Normalitas Galat

\begin{tabular}{llr}
\hline \multicolumn{2}{c}{ One-Sample Kolmogorov-Smirnov Test } \\
\hline Statistics & & Unstandardized Residual \\
\hline N & & 78 \\
Normal Parameters & Mean & $0 \mathrm{E}-7$ \\
& Std. Deviation & 13.88733258 \\
Most Extreme & Absolute & .129 \\
Differences & Positive & .084 \\
Kolmogorov-Smirnov Z & Negative & -.129 \\
Asymp. Sig. (2-tailed) & & 1.135 \\
a. Test distribution is Normal. & .152 \\
b. Calculated from data. &
\end{tabular}

Tabel 2. Uji Multikolinearitas

\begin{tabular}{llll}
\hline \multicolumn{2}{l}{ Coefficients $^{\mathbf{a}}$} & & \\
\hline Model & \multicolumn{2}{l}{ CollinearityStatistics } & \\
\cline { 3 - 4 } & & Tolerance & VIF \\
\hline & (Constant) & & \\
1 & Disiplin & .988 & 1.013 \\
& Motivasi Belajar & .988 & 1.013 \\
\hline
\end{tabular}

a. Dependent Variable: Prestasi Belajar Bahasa Indonesia

Tabel 3. Hasil Perhitungan Pengujian Koefisien Korelasi Ganda Variabel $X_{1}$ dan $\mathrm{X}_{2}$ terhadap $\mathrm{Y}$

\begin{tabular}{|c|c|c|c|}
\hline \multicolumn{4}{|c|}{ Model Summary } \\
\hline Model & $\mathrm{R}$ & R Square & Adjusted R SquareStd. Error of the Estimate \\
\hline 1 & $.412^{\mathrm{a}}$ & .170 & 14.071 \\
\hline
\end{tabular}

a. Predictors: (Constant), Motivasi Belajar, Disiplin 
Tabel 4. Hasil Perhitungan Pengujian Signifikansi Koefisien Regresi Variabel $\mathrm{X}_{1}$ dan $\mathrm{X}_{2}$ terhadap $\mathrm{Y}$

\begin{tabular}{|c|c|c|c|c|c|}
\hline \multicolumn{6}{|l|}{ ANOVA $^{a}$} \\
\hline Model & Sum of Squares & Df & Mean Square & $\mathrm{F}$ & Sig. \\
\hline Regression & 3032.921 & 2 & 1516.460 & 7.659 & $.001^{\mathrm{b}}$ \\
\hline Residual & 14850.066 & 75 & 198.001 & & \\
\hline Total & 17882.987 & 77 & & & \\
\hline
\end{tabular}

a. Dependent Variable: Prestasi Belajar Bahasa Indonesia

b. Predictors: (Constant), Motivasi Belajar, Disiplin

Tabel 5. Hasil Perhitungan Persamaan Regresi Ganda Variabel $\mathrm{X}_{1}$ dan $\mathrm{X}_{2}$ terhadap

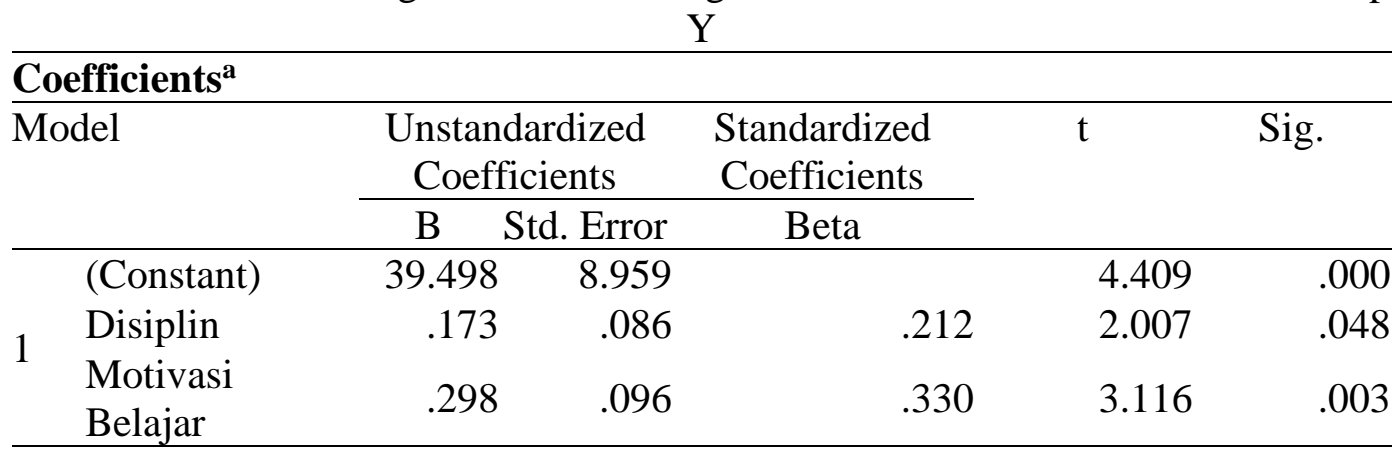

a. Dependent Variable: Prestasi Belajar Bahasa Indonesia

Dari data tersebut dapat dinyatakan bahwa terdapat pengaruh yang signifikan disiplin dan motivasi belajar secara bersama-sama terhadap prestasi belajar Bahasa Indonesia. Hal ini dibuktikan dengan perolehan nilai Sig. 0,001 < 0,05 dan $F_{h}=7,659$. Sementara itu, persamaan garis regresi ganda dapat dinyatakan dengan $\hat{Y}=39,498+0,173 \mathrm{X} 1+0,298$. Hal ini memiliki pengertian bahwa variabel disiplin dan motivasi belajar memberikan kontribusi positif terhadap variabel prestasi belajar Bahasa Indonesia. Dari tabel 4.8 juga dapat menjelaskan bahwa secara bersama-sama variable disiplin siswa dan motivasi belajar memberikan kontribusi sebesar $17 \%$ terhadap variable prestasi belajar Bahasa Indonesia.

Dari tabel dapat dinyatakan bahwa terdapat pengaruh yang signifikan disiplin terhadap prestasi belajar Bahasa Indonesia. Hal ini dibuktikan dengan perolehan nilai Sig. $0,048<0,05$ dan $t_{h}=2.007$. Dari hasil perhitungan tersebut dapat dinyatakan bahwa variabel disiplin memberikan kontribusi sebesar 5,28 \% terhadap peningkatan prestasi belajar bahasa Indonesia.

Dari tabel dapat dinyatakan bahwa terdapat pengaruh yang signifikan motivasi belajar terhadap prestasi belajar Bahasa Indonesia. Hal ini dibuktikan dengan perolehan nilai Sig. 0,003 $<0,05$ dan $t_{h}=3.116$. Berdasarkan hasil perhitungan dapat dinyatakan bahwa variabel motivasi belajar memberikan kontribusi sebesar 11,7 \% terhadap peningkatan prestasi belajar bahasa Indonesia.

Untuk menumbuhkan, mengembangkan, meningkatkan dan memelihara motivasi belajar walaupun dititikberatkan kepada usaha maksimal dari individu siswa, tetapi sangat dibutuhkan keterlibatan dan komitmen semua pihak, baik dari 
komponen penyelenggara maupun pengelola pendidikan untuk memfasilitasi berbagai sumber yang berkaitan dengan kelancaran proses belajar mengajar sehingga faktor-faktor yang mempengaruhi timbulnya motivasi belajar tercapai, sehingga apabila motivasi belajar siswa baik, maka dengan sendirinya akan meningkatkan prestasi belajar siswa itu sendiri.

Peningkatan prestasi belajar siswa dapat ditempuh dengan meningkatkan disiplin siswa secara lebih baik lagi. Penelitian ini menemukan bahwa dalam pengukuran disiplin siswa, secara rata-rata siswa meraih $68,7 \%$ dari kemungkinan skor teoritik tertinggi, sehingga disiplin siswa termasuk kategori cukup. Selain itu, prestasi belajar bahasa Indonesia siswa juga bisa ditingkatkan dengan meningkatkan Motivasi Belajar.

\section{SIMPULAN}

Berdasarkan uraian di atas, dapat disimpulkan bahwa terdapat pengaruh yang signifikan disiplin dan motivasi belajar secara bersama-sama terhadap prestasi belajar bahasa Indonesia siswa SMP Negeri di Kabupaten Bogor.

\section{DAFTAR PUSTAKA}

Arikunto, S. (2010). Prosedur penelitian suatu pendekatan praktik. Jakarta: Rineka Cipta.

Darmadi, H. (2009). Kemampuan Dasar Mengajar. Bandung: Pustaka Setia.

Malayu, S.P. (2002). Manajemen Sumber Daya Manusia (Edisi Revisi). Jakarta: Bumi Aksara.

Moenir, A.S. (2010). Manajemen Pelayanan Umum di Indonesia. Jakarta: PT Bumi Aksara.

Poerwadarminta, W.J.S. (2002). Kamus besar bahasa Indonesia. Jakarta: Balai Pustaka.

Slameto (2010). Belajar dan Faktor yang mempengaruhinya. Jakarta: Rineka. Cipta.

Setiawati, N.T.(1996). Hubungan antara Intelegensi, Kreativitas, dan Motivasi Berprestasi dengan prestasi belajar pada Siswa SMUN 8 Jakarta. Skripsi tidak dipublikasikan.

Soekadji, S. (1988). Ceramah Psikologi Remaja: Bagi Guru dan Kepala Sekolah. Jakarta:

Depdikbud RI.

Sugiyono. (2007). Metode penelitian kuantitatif dan kualitatif $R$ dan D. Bandung: Penerbit Alfabeta. 